\title{
Monoclonal Antibody CC-46
}

National Cancer Institute

\section{Source}

National Cancer Institute. Monoclonal Antibody CC-46. NCI Thesaurus. Code C29990.

A recombinant monoclonal antibody directed ag ainst colon cancer (CC) epitopes, tumorassociated glycoprotein 72 (TAG72). TAG72 is expressed in gastric, breast, pancreatic, colorectal, and ovarian carcinomas. ( $\mathrm{NCl04)}$ 